\title{
Two Schiff-base fluorescence probes based on triazole and benzotriazole for selective detection of $\mathrm{Zn}^{2+}$
}

\author{
Jiali Liu ${ }^{\mathrm{a}}$, Xia Menga, Hongdong Duan ${ }^{\mathrm{a}, *}$, Ting Xü ${ }^{\mathrm{b}}$, Zhaoyun Ding ${ }^{\mathrm{a}}$, Yu Liuc, \\ Lucian Lucia ${ }^{c}$
}

${ }^{a}$ School of Chemistry and Pharmaceutical Engineering, Qilu University of Technology, Jinan 250353, PR China

${ }^{\mathrm{b}}$ Chemical Technology Academy of Shandong Province, Jinan 250014, PR China

${ }^{\mathrm{c}}$ Key Lab of Pulp \& Paper Science and Technology, Qilu University of Technology, Ministry of Education, Jinan 250353, PR China

E-mail: hdduan67@gmail.com

\begin{abstract}
Two novel Schiff-base fluorescence probes based on triazole and benzotriazole were designed and synthesized. Corresponding orbital electron distribution and molecular geometry configurations of the compounds were predicted by density functional theory (DFT). Fluorescence properties of probes were detected by UV-vis and fluorescence spectra. Test results indicated that the probes had specific selectivity and high sensitivity for $\mathrm{Zn}^{2+}$ compared with metal ions examined $\left(\mathrm{Ag}^{+}\right.$, $\mathrm{Al}^{3+}, \mathrm{Cd}^{2+}, \mathrm{Cu}^{2+}, \mathrm{Fe}^{3+}, \mathrm{Hg}^{2+}, \mathrm{K}^{+}$and $\mathrm{Pb}^{2+}$. In addition, the detection limit of the probes toward $\mathrm{Zn}^{2+}$ was low down $10^{-9} \mathrm{M}$. Therefore, the probes should be potential application in both the environment and biological systems for the detecting of $\mathrm{Zn}^{2+}$.
\end{abstract}

Key words: fluorescence probes, triazole, benzotriazole, Schiff-base

\section{Introduction}


Zinc is an important essential trace element ( 10 to $15 \mathrm{mg}$ each day) in the human body. Many researchers reveal that $\mathrm{Zn}^{2+}$ plays a vital role in biological and metabolic function, including regulate catalytic activity of enzymes, neurotransmission, cellular transport, and apoptosis [1-3]. Moreover, Alzheimer's diseases, Parkinson's diseases, epilepsy and Ehlers-Danlos syndrome [4-6] are caused by deviation of $\mathrm{Zn}^{2+}$ concentrations in vivo biology. Excess of $\mathrm{Zn}^{2+}$ can also cause great damage to human health and environment. Therefore, it is of essential for people to find a simple and accurate method to detect the concentrations of $\mathrm{Zn}^{2+}$ in both the biological systems and environment.

Up to now, Some traditional techniques, such as spectrophotometric method with dithizone [7] and ionization mass spectrometry [8], which needs expensive equipment, cumbersome and time-consuming are very difficult to detect $\mathrm{Zn}^{2+}$. Comparing with these techniques, fluorescence probes have become a popular method for detecting $\mathrm{Zn}^{2+}$ because of their high selectivity, low detection limit and real-time monitoring. According to some researches [9-14], $\mathrm{Zn}^{2+}$ could cooperate with specific receptors of fluorescent probes. Such complexation changes the photophysical properties, and thus realizes high selectivity for $\mathrm{Zn}^{2+}$. Besides, a large number of $\mathrm{Zn}^{2+}$-selective fluorescence probes have been designed and synthesized based on photo-induced electrontransfer (PET) [15], intramolecular charge-transfer (ICT) [16], chelation-enhanced fluorescence (CHEF) [17], and fluorescence resonance energy transfer (FRET) [18] theories, respectively. However, there still exists some drawback among the reported fluorescence probes, e.g. the detection limit of probes is 
restricted[19-22], some of the sensors are hard to synthesize [23], "turn-on" responses and selectivity are relatively scarce [24], optical properties are interferenced from other metal ions, such as $\mathrm{Cd}^{2+}$ which exhibits highly similar chemical properties as $\mathrm{Zn}^{2+}$. Therefore, to develop some low cost, easily-prepared, high selectivity and sensitivity $\mathrm{Zn}^{2+}$ fluorescence probes are expected to remain a challenging.

Herein, more and more researchers focus on the development of Schiff-base fluorescence probes with high selectivity, sensitivity, low detection limit and real-time monitoring[25-28]. In view of previous researchers, we find Schiff-base fluorescence probes containing $\mathrm{C}=\mathrm{N}$ structure with a lone electron pair have good ability to coordinate with metal ions. Compounds with an unbridged $\mathrm{C}=\mathrm{N}$ structure are often nonfluorescent due to the $\mathrm{C}=\mathrm{N}$ isomerization. By combining specific metal ions, the $\mathrm{C}=\mathrm{N}$ isomerization is prevented, specific chelating effect is caused, thereby fluorescent property is enhanced [29]. Therefore, we incorporated a special functional groups of $\mathrm{sp}^{2}$ nitrogen $(-\mathrm{CH}=\mathrm{N}-)$ into our probe design. In particular, we expected that fluorescence probes had relatively lower detection limits in the range detected. At the same time, considering that triazole and benzotriazole exhibit excellent photophysical property and low cost $[30,31]$, we designed two simple Schiff-base fluorescence probes on the basis of them, which played high selectivity and sensitivity for $\mathrm{Zn}^{2+}$ compared with other metal ions.

\section{Experimental}

\subsection{Materials and measurements}

Unless otherwise stated, reagents and materials were obtained from commercial 
suppliers at analytical grade and used without further purification. Triazole, benzotriazole, $p$-fluorobenzaldehyde and $p$-phenylenediamine were purchased from Sinopharm Chemical Reagent Co., Ltd. Distilled water was used throughout the experiment. Metal ions used in fluorescence analysis were prepared from the corresponding inorganic salts.

Reactions were monitored by TLC. ${ }^{1} \mathrm{H}$ NMR spectra were taken on a Bruker Avance $400 \mathrm{MHz}$ NMR Spectrometer with chemical shifts reported in ppm (in DMSO-d6). Dimethyl sulfoxide (DMSO) was used as the solvent. Elemental analysis was recorded on SGWX-4 micro melting point apparatus. Fourier Transform Infrared (FT-IR) spectra were measured using TENSOR 27 FT-IR spectrometer. Absorption spectra were obtained on a MPC-2600 UV-vis spectrofluorometer. N,N-dimethylformamide (DMF) was used as the solvent. Fluorescent measurements were conducted on F-4500 (Hitachi) spectrofluorometer.

\subsection{Synthesis}

\subsubsection{Synthesis of compound 1}

The synthesis route of compound 1 was showed in scheme 1. 1,2,4-Triazole (0.069 g, $10 \mathrm{mmol})$ and $p$-fluorobenzaldehyde $(1.24 \mathrm{~g}, 10 \mathrm{mmol})$ were dissolved in DMF solution $(20 \mathrm{~mL})$, then anhydrous potassium carbonate $(1.66 \mathrm{~g}, 12 \mathrm{mmol})$ were added slowly under stirring. The mixture was refluxed under $110^{\circ} \mathrm{C}$ for $12 \mathrm{~h}$, and then cooled down to room temperature. The precipitate was filtered and the filtrate was extracted three times with $100 \mathrm{~mL}$ acetic ether. The combined organic extracts were dried over anhydrous sodium sulfate and left overnight. The soild was filtered and the 
concentrate was chromatographed on a silica gel column using methanol: chloroform $=1: 9$ as an eluent. Yellow powder was dried in vacuum over $6 \mathrm{~h}$ to obtain compound $1\left(1.02\right.$ g, 59\%); m.p. $143-146^{\circ} \mathrm{C}$; IR $\left(\mathrm{KBr}, \mathrm{cm}^{-1}\right): 1689,1604,1519,1207,981,837$ $\mathrm{cm}^{-1} ;{ }^{1} \mathrm{H}$ NMR (DMSO-d $\left.6,400 \mathrm{MHz}\right): \delta 10.07$ (s, 1H, CHO ), 8.67 (s, 1H, triazole H), $8.16(\mathrm{~s}, 1 \mathrm{H}$, triazole $\mathrm{H}), 8.04(\mathrm{~d}, 2 \mathrm{H}, \mathrm{ArH}), 7.92(\mathrm{~d}, 2 \mathrm{H}, \mathrm{ArH})$.

\subsubsection{Synthesis of compound 2}

The synthesis route of compound 2 was showed in scheme 1 . Compound 1 (0.173 $\mathrm{g}, 1 \mathrm{mmol})$ and $p$-phenylenediamine $(0.054 \mathrm{~g}, 0.5 \mathrm{mmol})$ were dissolved into DMF (4 $\mathrm{mL}$ ), and then five drops of glacial acetic acid were added into mixture under stirring. The temperature was maintained at $100^{\circ} \mathrm{C}$ for $5 \mathrm{~h}$ under reflux, and then cooled down to room temperature. Distilled water $(20 \mathrm{~mL})$ was added into mixture and obtained precipitate. The yellow precipitate was filtered and washed several times with warm water $\left(50^{\circ} \mathrm{C}\right)$. Product was dried in vacuum over $6 \mathrm{~h}$ to obtain compound $2(0.13 \mathrm{~g}$, 63\%); m.p. $120-122^{\circ} \mathrm{C}$; IR (KBr, cm $\left.{ }^{-1}\right): 1624,1517,1406,1195,850,675 \mathrm{~cm}^{-1} ;{ }^{1} \mathrm{H}$ NMR (DMSO-d $6,400 \mathrm{MHz}): \delta 9.42(\mathrm{~d}, \mathrm{H}$, triazole H), 8.29 (d, 2H, ArH), $8.11(\mathrm{~s}, 2 \mathrm{H}$, ArH), 8.04-7.94 (m, 2H, ArH), 7,16 (d, H, triazole H), 6.65-6.52 (m, H, HC=N).

\subsubsection{Synthesis of compound 3}

The synthesis route of compound 3 was showed in scheme 1. Benzotriazole (1.3 $\mathrm{g}, 8.4 \mathrm{mmol})$ and anhydrous potassium carbonate $(2.3 \mathrm{~g}, 16.8 \mathrm{mmol})$ were added to a $50 \mathrm{~mL}$ boiling flask-4-neck and dissolved in DMF solution $(20 \mathrm{~mL})$. The reaction mixture was stirred under reflux. The temperature was maintained at $80-90^{\circ} \mathrm{C}$. After reaction for $30 \mathrm{~min}, p$-fluorobenzaldehyde $(1.04 \mathrm{~g}, 8.4 \mathrm{mmol})$ was added into mixture, 
and then kept the mixture for 8 - $9 \mathrm{~h}$ under the above-mentioned temperature. When the end of the reaction, the mixture was cooled to room temperature, and poured into ice water $(50 \mathrm{~mL})$ and left overnight, yellow precipitate was obtained. The precipitate was filtered, washed three times with deionized water and recrystallized with absolute ethanol. Product was dried in vacuum over $6 \mathrm{~h}$ to obtain compound 3 (1.69 g, 90\%); m.p. $155-157^{\circ} \mathrm{C}$; IR $\left(\mathrm{KBr}, \mathrm{cm}^{-1}\right): 1691,1601,1510,1452,1071,826,734 \mathrm{~cm}^{-1} ;{ }^{1} \mathrm{H}$ NMR (DMSO-d $6,400 \mathrm{MHz}): \delta 10.12(\mathrm{~s}, 1 \mathrm{H}, \mathrm{CHO}), 8.53(\mathrm{~d}, 1 \mathrm{H}, \mathrm{ArH}), 8.21(\mathrm{~d}, 4 \mathrm{H}$, ArH), 8.08 (s, 1H, ArH), 7.71 (s, 1H, ArH), 7.55 (s, 1H, ArH).

\subsubsection{Synthesis of compound 4}

The synthesis route of compound 4 was showed in scheme 1 . Compound 3 ( $0.1 \mathrm{~g}$, $0.45 \mathrm{mmol})$ and $p$-phenylenediamine $(0.024 \mathrm{~g}, 0.225 \mathrm{mmol})$ were dissolved in DMF (4 mL) under stirring and reflux. Then four drops of glacial acetic acid were added into mixed solution. The temperature was maintained at $80^{\circ} \mathrm{C}$ for $2 \mathrm{~h}$, a large number of yellow soild appeared as the reaction process. The mixture was cooled down to room temperature and distilled water $(50 \mathrm{~mL})$ was added. The precipitate was filtered, washed thoroughly with warm water $\left(40^{\circ} \mathrm{C}\right)$, and then dried in vacuum over $6 \mathrm{~h}$ to obtain compound 4 (0.08 g, 65\%); m.p. $330-333{ }^{\circ} \mathrm{C}$; IR (KBr, $\left.\mathrm{cm}^{-1}\right): 3060,1601,1513$, 1450, 1244, 836, $745 \mathrm{~cm}^{-1} ;{ }^{1} \mathrm{H}$ NMR (DMSO-d $\left.6,400 \mathrm{MHz}\right): \delta 8.66(\mathrm{~d}, 1 \mathrm{H}, \mathrm{ArH}), 8.21$ (d, 4H, ArH), $7.99(\mathrm{~d}, 1 \mathrm{H}, \operatorname{ArH}), 7.86(\mathrm{~s}, 1 \mathrm{H}, \mathrm{C}=\mathrm{N}), 7.63(\mathrm{~s}, 1 \mathrm{H}, \operatorname{ArH}), 7.50(\mathrm{~s}, 1 \mathrm{H}$, ArH), 7.40 (s, 2H, ArH).

\section{Results and discussion}

\subsection{Design and synthesis of compound 2 and compound 4}


As shown in Scheme 1, the compound 2 and 4 can be synthesized in two steps from commercially available chemicals in high yield. Details for synthesis are described in the experiment section. Structures were characterized by ${ }^{1} \mathrm{H}$ NMR and FT-IR spectrometer.

\subsection{Theoretical calculation}

The calculation of a wide range of molecular properties with density functional theory makes a close connection between experiment and theory [32]. Through theoretical calculation, the molecular structures of the compounds were optimized, and their performance was predicted by the Gaussian 03 software package. Generally speaking, most of organic molecules exist in the form of lowest energy [33]. Through optimized molecular geometry configurations of the compounds at the DFT (B3LYP/6-31G*) level, we had obtained the initial conformation with lower energy. At the same time, space steric effect was reduced, molecular planarity was enhanced. Through overview literatures, most of compounds containing benzene ring and heterocyclic ring could product fluorescence. The bigger the conjugate system, the stronger the fluorescence intensity. Furthermore, rigid planar structure could result in strong fluorescence $[34,35]$. As shown in Fig.1 and 2, compounds 2 and 4 had highly symmetrical rigid planar molecular structures. It could be predicted that compounds could product strong fluorescence.

Corresponding orbital electron distribution of compounds were also predicted in Fig. 1 and 2. Parallel p orbitals on the HOMO and LUMO were almost all over the entire molecular structure, and it could be demonstrated that compound 2 and 4 had 
larger delocalized $\pi$-bond. As shown in Fig. 1, there were frontier orbital electron density overlaps between LUMO and LUMO+1, between HOMO and HOMO-1, respectively, which shown that compound 2 was very easy to carry out electronic transition. Similar results could be found on compound 4. Because all the energies are negative, compounds may be combined with metal ions easily. Energy gap $(\Delta \mathrm{E})$ between HOMO and LUMO reflects stability of compounds, the smaller energy gap, the more easily compound is excited [36]. As shown in Table $1, \Delta \mathrm{E}_{2}>\Delta \mathrm{E}_{4}$, it could be predicted that maximum absorption wavelength of compound 4 was larger than 2 . Therefore, compound 2 and 4 had strong molecular planarity and large conjugated $\pi$-bonds, it was expected that the compounds became good fluorescent materials.

\subsection{The optical properties of compounds 2 and 4}

\subsubsection{Reaction time and $\mathrm{pH}$-sensitive investigation}

The response time between fluorescence probes and $\mathrm{Zn}^{2+}$ was detected with the addition of $10 \mu \mathrm{M} \mathrm{Zn}^{2+}$, the results were shown in Figure 3. Upon the addition of $\mathrm{Zn}^{2+}$, a fluorescence signal was immediately initiated and the reaction was completed within $10 \mathrm{~min}$. Thus, the reaction of probes and $\mathrm{Zn}^{2+}$ should be detected after $10 \mathrm{~min}$. Compared with the majority of $\mathrm{Zn}^{2+}$ fluorescent probes which were reported ( the response time is $20 \mathrm{~min}$ to $2 \mathrm{~h}$ ) $[37,38]$, compound 2 and 4 could respond to $\mathrm{Zn}^{2+}$ more rapidly.

The $\mathrm{pH}$-sensitivity of the fluorescence probes and $\mathrm{Zn}^{2+}$ were detected by fluorescence emission spectroscopy. As shown in Figure 4, the fluorescence of compound 2 and 4 was found to be remained stable between $\mathrm{pH} 6$ to 9 . In the other 
words, it is possible for probes to detect $\mathrm{Zn}^{2+}$ in a biological range of $\mathrm{pH}$ values.

\subsubsection{UV-vis absorption spectra}

All UV-vis spectroscopy was obtained after the addition of different metal ions in DMF solution. The concentration of mixture was maintained at $1 \times 10^{-5} \mathrm{M}$ on MPC-2600 spectrometer. As shown in Fig. 5 and 6, in the absence of cations, the maximum absorption wavelength of compound 2 and 4 appeared at $361 \mathrm{~nm}$ and 369 $\mathrm{nm}$, respectively. It was caused by $\pi-\pi^{*}$ transitions of $\mathrm{C}=\mathrm{N}$ group. Relative to compound 2, compound 4 had much higher absorbance and showed a red shift, as result of its stronger electron donating ability of introduced benzene ring and stronger conjugate system $[39,40]$. In addition, appropriate coordination geometry configuration, metal ions radius and affinity with ligand also affect UV-vis spectrum [41]. With the addition of metal ions $\left(\mathrm{Zn}^{2+}, \mathrm{Ag}^{+}, \mathrm{Al}^{3+}, \mathrm{Cd}^{2+}, \mathrm{Cu}^{2+}, \mathrm{Fe}^{3+}, \mathrm{Hg}^{2+}, \mathrm{K}^{+}\right.$and $\mathrm{Pb}^{2+}$ ), the maximum absorption wavelength of compound 2 and 4 appeared at 365 $\mathrm{nm}$ and $372 \mathrm{~nm}$, respectively, and showed a red shift. Above results showed formation of new complex with combination of cations and the lone electron pair of $\mathrm{C}=\mathrm{N}$. As

Fig 5 showed, upon the addition of $\mathrm{Zn}^{2+}$ ion, a significant absorption band in the UV-vis spectra appeared. Compared with $\mathrm{Zn}^{2+}$, other metal ions $\left(\mathrm{Ag}^{+}, \mathrm{Al}^{3+}, \mathrm{Cd}^{2+}\right.$, $\mathrm{Cu}^{2+}, \mathrm{Fe}^{3+}, \mathrm{Hg}^{2+}, \mathrm{K}^{+}$and $\left.\mathrm{Pb}^{2+}\right)$ at the same concentration showed weaker absorption intensity. Compound 4 also revealed the above-mentioned phenomena in Fig. 6. In summary, the compounds had stronger complexing ability with $\mathrm{Zn}^{2+}$.

\subsubsection{Fluorescence spectra}

Structures containing electron withdrawing group conjugated to electron donating 
group made these compounds as good fluorescent materials. In order to assesse the spectroscopic characteristics of probes, a series of experiments were designed to measure fluorescent intensity. The fluorescence spectra of compounds were obtained by exciting at their maximum wavelength, and then results were showed in Fig. 7 and 8. At $1 \times 10^{-5} \mathrm{M}$, compounds exhibited relatively strong fluorescence emission at 338 $\mathrm{nm}$ and $342 \mathrm{~nm}$, respectively. Under the same conditions, relative to compound 2, the higher fluorescence intensity and a red shift of fluorescence emission peak of compound 4 were derived from the higher molecular weight and the stronger molecular conjugate degree of introduced benzene ring. On the other hand, fluorescence were considered to arise from the lowest excited singlet state and terminate in the ground state $[42,43]$. Increase of the size of the aromatic conjugated system resulted in decrease of the energy gap between the ground and excited states, so that the compound 4 had larger emission wavelength. As shown in theoretical calculation, the energy difference between HOMO and LUMO of compound 4 was also lower than that of compound 2, which agrees well with the results of fluorescence spectra. As Table 2 shown, the stokes shift has been calculated by the maximum absorption band $\left(\lambda_{\text {abs }}\right)$ and the maximum emission band $\left(\lambda_{\text {em }}\right)$. The stokes shift is negative, it is anti-stock shift phenomenon.

\subsubsection{Selectivity of metal ions}

Selectivity of compounds for different metal ions $\left(\mathrm{Zn}^{2+}, \mathrm{Ag}^{+}, \mathrm{Al}^{3+}, \mathrm{Cd}^{2+}, \mathrm{Cu}^{2+}\right.$, $\mathrm{Fe}^{3+}, \mathrm{Hg}^{2+}, \mathrm{K}^{+}$and $\mathrm{Pb}^{2+}$ ) were detected by a series of experiments. Related fluorescence spectra in the present and absence of metal ions were obtained. The most 
important criteria for a selective cationic probe was ability to detect specific cation. As Fig. 7 showed, with the addition of metal ions, the different degrees of enhancement of fluorescence intensity of compound 2 emerged quickly. The isomerisation of $\mathrm{C}=\mathrm{N}$ double bond resulted in weak or non fluorescence emission. After metal ions were added into the mixture solutions, a selective chelation-enhanced fluorescence (CHEF) effect was observed, a new $\pi$-conjugated structure was formed, and then fluorescence enhancement of Schiff-base emerged [44]. In addition, emission change was more sensitive for the addition of $\mathrm{Zn}^{2+}$, in other words, compound 2 had high selectivity to $\mathrm{Zn}^{2+}$. In contrast, no significant changes were observed after adding $\mathrm{Ag}^{+}, \mathrm{Al}^{3+}, \mathrm{Fe}^{3+}$ and $\mathrm{K}^{+}$because of their low affinity with ligand. Although $\mathrm{Hg}^{+}, \mathrm{Cu}^{2+}, \mathrm{Hg}^{3+}$ and $\mathrm{Pb}^{2+}$ had a certain degree of fluorescence enhancement, the intensity was smaller compared with $\mathrm{Zn}^{2+}$. Detection limit of fluorescent probe is a very important parameter in ion detecting. As Fig. 9 shown, when the concentration of mixture solution was diluted from $1 \times 10^{-5} \mathrm{M}$ to $1 \times 10^{-9} \mathrm{M}$, the compound 2 still showed good fluorescence intensity. These data indicated that the compound had potential applications in biological sensing, as concentration of $\mathrm{Zn}^{2+}$ in human body was reported to maintain a millimolar level. Thus, compound 2 could be used as an excellent selective fluorescence chemosensor for $\mathrm{Zn}^{2+}$.

Cation recognition ability of compound 4 was detected by the above same method. As Fig. 10 shown, fluorescence intensity in the presence of $\mathrm{Zn}^{2+}$ was stronger than that in the presence of other ions $\left(\mathrm{Ag}^{+}, \mathrm{Al}^{3+}, \mathrm{Cd}^{2+}, \mathrm{Cu}^{2+}, \mathrm{Fe}^{3+}, \mathrm{Hg}^{2+}, \mathrm{K}^{+}\right.$and $\left.\mathrm{Pb}^{2+}\right)$. Thus, the compound had the strongest chelating ability with $\mathrm{Zn}^{2+}$. Theoretical 
calculation showed that the compound 4 had greater energy. With the addition of $\mathrm{Zn}^{2+}$, energy of highest occupied molecular orbital for ligand is decreased, which made it very easy to be excited. On the other hand, compounds containing a covalently bridged $\mathrm{C}=\mathrm{N}$ double bond structure had a very significant fluorescence enhancement. With the combination of $\mathrm{Zn}^{2+}$ and lone electron pair of $\mathrm{C}=\mathrm{N}$ in Schiff base, the twist angle of structure decreased, the rigidity of system increased, and CHEF emerged. Coordination geometry configuration and conjugate structure have a great influence on the selectivity of compounds [45]. As Fig. 10 shown, when concentration of compound 4 were diluted to $1 \times 10^{-9} \mathrm{M}$, fluorescent intensity can still be detected. These results exhibited that compound 4 could be useful as a fluorescent probe for selective detection of $\mathrm{Zn}^{2+}$.

\subsubsection{The concentration of $\mathrm{Zn}^{2+}$ investigation}

The stoichiometric ratio of the $1.0 \mu \mathrm{M}$ probes and $\mathrm{Zn}^{2+}$ were researched by fluorescence titration. As shown in Fig.11 and 12, upon the addition of $\mathrm{Zn}^{2+}(0-1.2$ $\mu \mathrm{M})$, the emission intensity was observed and showed a linear enhancement. When the concentration of $\mathrm{Zn}^{2+}$ was up to $1.0 \mu \mathrm{M}$, emission intensity of probes were found to remain stable which implied the $1: 1$ binding of probes to $\mathrm{Zn}^{2+}$. Through the above phenomenon, we were able to deduce a possible coordination mode, that is, $\mathrm{N}$ atoms from 5-membered heterocyclic and $\mathrm{C}=\mathrm{N}$ double bonds can form an efficient binding pocket for $\mathrm{Zn}^{2+}$ with 1:1 stoichiometry. From the emission intensity by following the modified Benesi-Hidebrand equation, the association constants of compound 2 and 4 were calculated as $4.53 \times 10^{6} \mathrm{M}^{-1}$ and $3.08 \times 10^{6} \mathrm{M}^{-1}$ [46-49]. Detection limits 
calculated on the basis of equation $C_{L}=3 S_{b} / S$ were as low as $3.5 \times 10^{-9} \mathrm{M}$ and $2.8 \times$ $10^{-9} \mathrm{M}$ respectively. Ideal detection limits were consistent with the experimental values, implying nM range of detection limit is desirable.

\section{Conclusions}

In conclusions, two novel fluorescent probes with high selectivity based on triazole, benzotriazole have been designed and synthesized successfully. The investigated results showed that the compounds have specificity for $\mathrm{Zn}^{2+}$ compared with metal ions examined. In addition, compared with World Health Organization detection level, the detection limits $\left(10^{-9} \mathrm{M}\right)$ of compounds were lower. Thus, it can be concluded that compounds 2 and 4 have underlying applications for the detection $\mathrm{Zn}^{2+}$ in both the environment and physiological sciences.

\section{Acknowledgments}

This work was supported by the National Science Foundation of China (Grant No. 31270626) and Shandong Province Science and Technology Development Plan (Grant No. 2014GGX102023).

\section{References}

[1] Wolfgang Maret, Zinc coordination environments in proteins determine zinc functions, J. Trace Elem. Med Biol. 19(2005)7-12.

[2] S. Herga, J.-G. Berrin, J. Perrier, A. Puigserver, T. Giardina, Identification of the 
zinc binding ligands and the catalytic residue in human aspartoacylase, an enzyme involved in Canavan disease, 580 (2006) 5899-5904.

[3] D.K. Perry, M.J. Smyth, H.R. Stennicke, G.S. Salvesen, P. Duriez, G.G. Poirier, Y.A. Hannun, Zinc is a potent inhibitor of the apoptotic protease, caspase-3. A novel target for zinc in the inhibition of apoptosis, J. Biol. Chem. 272 (1997) 18530-18533.

[4] Tudor, Zalewski, Ratnaike, Zinc in health and chronic disease , J. Nutr. Health Aging. 9(2005) 45-51.

[5] Giovanni Forte, Alessandro Alimonti, Nicola Violante, Marco Di Gregorioa, Oreste Senofonte, Francesco Petrucci, Giuseppe Sancesario, Beatrice Bocca, Calcium, copper, iron, magnesium, silicon and zinc content of hair in Parkinson's disease, J. Trace Elem. Med Biol. 19 (2005) 195-201.

[6] Kiilholma, M. Gronroos, V. Nanto, R. Paul, Pregnancy and Delivery in Ehlers-Danlos Syndrome: Role of copper and zinc, Acta. Obstet. Gyn. Scan. 63(1984) 437- 439 .

[7] Nabrzyski, Michal, Spectrophotometric method for copper and mercury determination in the same food sample using dithizone and lead diethyldithiocarbamate, Anal. Chem. 47(1975) 552- 553.

[8] Burnaby Munson, Development of chemical ionization mass spectrometry, Int. J. Mass spectrum, 200(2000) 243-251.

[9] Faiz-Ur-Rahman XXXX, Amjad Ali, Rong Guo, Jia Tia, Hui Wang, Zhan-Ting Li, Dan-Wei Zhang, Methionine-derived Schiff base as selective fluorescent "turn-on" chemosensor for $\mathrm{Zn}^{2+}$ in aqueous medium and its application in living cells imaging. 
Sens. Actuators B: Chem. 211 (2015) 544-550.

[10] Gyeong Jin Park, Hyun Kim, Jae Jun Lee, Yong Sung Kim, Sun Young Lee, Suyeon Lee, Insup Noh, Cheal Kim, A highly selective turn-on chemosensor capable of monitoring $\mathrm{Zn}^{2+}$ concentrations in living cells and aqueous solution, Sens. Actuators B: Chem. 215 (2015) 568-576.

[11] Masayori Hagimori, Takashi Temma, Naoko Mizuyama, Takuhiro Uto, Yasuchika Yamaguchi, Yoshinori Tominaga, Takahiro Mukai, Hideo Saji, A high-affinity fluorescent $\mathrm{Zn}^{2+}$ sensor improved by the suppression of pyridine-pyridone tautomerism and its application in living cells, Sens. Actuators B: Chem. 213 (2015) 45-52.

[12] Ting Xu, Hongdong Duan, Xingjian Wang, Xia Meng, Juan Bu, Fluorescence sensors for $\mathrm{Zn}^{2+}$ based on conjugated indole Schiff base, Spec. Acta Part A. 138(2015) 603-608.

[13] C.Arivazhagan, Rosmita Borthakur, and Sundargopal Ghosh, Ferrocene and Triazole-Appended Rhodamine Based Multisignaling Sensors for $\mathrm{Hg}^{2+}$ and Their Application in Live Cell Imaging, Organometallics,34(2015) 1147-1155.

[14] HN Kim, MH Lee, HJ Kim, JS Kim, J Yoon, A new trend in rhodamine-based chemosensors: application of spirolactam ring-opening to sensing ions, Chem. Soc. Rev.,37(2008) 1465-1472.

[15] Shawn C. Burdette and Stephen J. Lippard, The rhodafluor family. An initial study of potential ratiometric fluorescent sensors for $\mathrm{Zn}^{2+}$, Inorg. Chem. 41(2002) 6816-6823. 
[16] Guanjun Zhang, Shiming Bi, Longfeng Song, Feng Wang, Jianjun Yu, Limin Wang, New diketopyrrolopyrrole (DPP) derivative as fluorescent probe for $\mathrm{Zn}^{2+}$, Dyes and Pigments, 99 (2013) 779-786.

[17] Sahana A, Banerjee A, Lohar S, Sarkar B, Mukhopadhyay SK, Das D, Rhodamine-based fluorescent probe for $\mathrm{Al}^{3+}$ through time-dependent PET-CHEF-FRET processes and its cell staining application, Inorg. Chem.52(2013) $3627-3633$.

[18] E. Manandhar, J.H. Broome, J. Myrick, W. Lagrone, P.J. Cragg, K.J. Wallace, A pyrene-based fluorescent sensor for $\mathrm{Zn}^{2+}$ ions: a molecular 'butterfly', Chem. Commun. 47 (2011) 8796-8798.

[19] Jun Ye, Jian Xiong, Runcang Sun, The fluorescence property of Schiff's bases of carboxymethyl cellulose, Carbohydr. Polym. 88 (2012) 1420-1424.

[20] X Chen, T Pradhan, F Wang, JS Kim, J Yoon, Fluorescent chemosensors based on spiroring-opening of xanthenes and related derivatives, Chem. Rev., 112(2012) $1910-1956$.

[21] M Beija, CAM Afonso, JMG Martinho, Synthesis and applications of rhodamine derivatives as fluorescent probes, Chem. Soc. Rev., 38(2009) 2410-2433.

[22] G Sivaraman, T Anand, D Chellappa, A fluorescence switch for the detection of nitric oxide and histidine and its application in live cell imaging, Chempluschem, 79(2004) 1761-1766.

[23] W. Jiang, Q. Fu, H. Fan, W. Wang, An NBD fluorophore-based sensitive and selective fluorescent probe for zinc ion, Chem. Commun. (2008) 259-261. 
[24] Artur Jasinski, Marcin Guzinski, Grzegorz Lisak, Johan Bobacka, Maria Bochenska, Solid-contact lead(II) ion-selective electrodes for potentiometric determination of lead(II) in presence of high concentrations of $\mathrm{Na}(\mathrm{I}), \mathrm{Cu}(\mathrm{II}), \mathrm{Cd}(\mathrm{II})$, Zn(II), Ca(II) and Mg(II), Sens. Actuators B: Chem. 218 (2015) 25-30.

[25] Yi Chen, Nan Xie, Fluorescence detection of conversion of phenolic Schiff bases to benzoxazoles, J. Photochem. Photobiol., A, 179 (2006) 320-323.

[26] Dong Zhang, Zhipeng Zang, Xiaoyan Zhou, Yan Zhou, Xiaoliang Tang, Ruiping Wei, Weisheng Liu, A selective fluorescence probe for yttrium(III) based on acylhydrazone Schiff base, Inorg. Chem. Commun. 12 (2009) 1154-1156.

[27] Cheng-Yi Lu, Yen-Wen Liu, Pei-Ju Hung, Chin-Feng Wan, An-Tai Wu, A turn-on and reversible Schiff-base fluorescence sensor for $\mathrm{Al}^{3+}$ ion, Inorg. Chem. Commun. 35 (2013) 273-275.

[28] T. Sanjoy Singh, Pradip C. Paul, Harun A.R. Pramanik, Fluorescent chemosensor based on sensitive Schiff base for selective detection of $\mathrm{Zn}^{2+}$, Spectrochim. Acta Part A, 121(2014) 520-526.

[29] Xingjian Wang, Ting Xu, Hongdong Duan, Schiff base fluorescence probes for $\mathrm{Cu}^{2+}$ based on imidazole and benzimidazole, Sens. Actuators B: Chem. 214 (2015) $138-143$.

[30] Hyemi Kim, Sunho Lee, Jihyun Lee, Jinsung Tae, Rhodamine triazole-based fluorescent probe for the detection of $\mathrm{Pt}^{2+}$, Org. Lett. 12(2010) 5342-5345.

[31] Yi-Cheng Shen, Zhao-Ji Li, Jian-Kai Cheng, Ye-Yan Qin, Yuan-Gen Yao, Benzotriazole controlled unusual building blocks in two zinc complexes and their 
fluorescence properties, Inorg. Chem. Commun. 10(2007) 888-890.

[32] Maylis Orio, Dimitrios A. Pantazis, Frank Neese, Density functional theory, Photosynth. Res. 102 (2009) 443-453.

[33] Xiao-Wei Fan, Xue-Hai Ju, He-Ming Xiao, Density functional theory study of piperidine and diazocine compounds, J. Hazard. 156(2008) 342-347.

[34] Joseph Ponniah S, Subrat Kumar Barik, Arunabha Thakur, R. Ganesamoorthi, and SundargopalGhosh, Triazolyl Alkoxy Fischer Carbene Complexes in Conjugation with Ferrocene/Pyrene as Sensory Units: Multifunctional Chemosensors for Lead(II), Copper(II), and Zinc(II) Ions, Organometallics, 33(2014) 3096-3107.

[35] Tayade, K; Sahoo, SK; Bondhopadhyay, B; Bhardwaj, VK; Singh, N; Basu, A; Bendre, R; Kuwar, A Bendre, R, Highly selective turn-on fluorescent sensor for nanomolar detection of biologically important $\mathrm{Zn}^{2+}$ based on isonicotinohydrazide derivative: Application in cellular imaging, 61(2014) 429-433.

[36] A. Pérez-Garrido, F. Alhama, J.D. Catalá, Electronic structure of fullerenes with defects, Chem. Phys. 278 (2002) 71-78.

[37] Gandhi Sivaraman, Vijayaraj Sathiyaraja, Duraisamy Chellappa, Turn-on fluorogenic and chromogenic detection of Fe(III) and its application in living cell imaging: Journal of Luminescence ,145(2014) 480-485.

[38] Thangaraj Anand, Gandhi Sivaraman, Murugan Iniya, Ayyanar Siva, Duraisamy Chellappa, Aminobenzohydrazide based colorimetric and 'turn-on' fluorescence chemosensor for selective recognition of fluoride, Analytica chimica Acta., 876(2015) $1-8$. 
[39] Thangaraj Anand, Gandhi Sivaraman, Ayyavu Mahesh, Duraisamy Chellappa, Aminoquinoline based highly sensitive fluorescent sensor for lead(II) and aluminum(III) and its application in live cell imaging, 853(2015) 596-601.

[40] Gandhi Sivaraman, Balasubramanian Vidya and Duraisamy Chellappa, Rhodamine based selective turn-on sensing of picric acid, RSC Adv. 4(2014) 30828-30831.

[41] D.L. Melton, D.G. VanDerveer, R.D. Hancock, Complexes of greatly enhanced thermodynamic stability and metal Ion size-based selectivity, formed by the highly preorganized non-macrocyclic ligand 1,10-phenanthroline-2,9-dicarboxylic acid. A thermodynamic and crystallographic study. Inorg. Chem. 45(2006) 9306-9314.

[42] Dr. Gandhi Sivaraman, Thangaraj Anand and Prof. Dr. Duraisamy Chellappa, A Fluorescence Switch for the Detection of Nitric Oxide and Histidine and Its Application in Live Cell Imaging, ChemPlusChem , 79(2014) 1761-1766.

[43] Gandhi Sivaraman, Thangaraj Anand and Duraisamy Chellappa, Turn-on fluorescent chemosensor for $\mathrm{Zn}$ (II) via ring opening of rhodamine spirolactam and their live cell imaging, Analyst 137(2012) 5881-5884.

[44] Lina Wang, Wenwu Qin, Weisheng Liu, A sensitive Schiff-base fluorescent indicator for the detection of $\mathrm{Zn}^{2+}$, Inorg. Chem. Commun. 13 (2010) 1122-1125.

[45] D.L. Melton, D.G. VanDerveer, R.D. Hancock, Size-based selectivity, formed by the highly preorganized non-macrocyclic ligand 1,10-phenanthroline-2,9-dicarboxylic acid. Athermodynamic and crystallographic study, Inorg. Chem.4 (2006) 9306-9314. 
[46] Khosro Zangeneh Kamali, Alagarsamy Pandikumar, Gandhi Sivaraman, Hong Ngee Lim, Stephen Paul Wren, Tong Sun and Nay Ming Huang, Silver@graphene oxide nanocomposite-based optical sensor platform for biomolecules, RSC Advances, 5(2015) 17809-17816.

[47] Thangaraj Anand, Gandhi Sivaraman, Palpandi Anandh, Duraisamy Chellappa, Subbaiah Govindarajan, Colorimetric and turn-on fluorescence detection of $\operatorname{Ag}(\mathrm{I})$ ion, Tetrahedron Letters 55(2014) 671-675.

[48] Rong-Rong Zhang, Jin-Feng Zhang, Sheng-Qing Wang, Yan-Long Cheng, Jun-Ying Miao, Bao-Xiang Zhao, Novel pyrazoline-based fluorescent probe for detecting thiols and its application in cells, Spectrochimica Acta Part A, Molecular and Biomolecular Spectroscopy, 137(2015) 450-455.

[49] Thangaraj Anand, Gandhi Sivaraman, Duraisamy Chellappa, Quinazoline copper(II) ensemble as turn-on fluorescence sensor for cysteine and chemodosimeter for NO, Journal of Photochemistry and Photobiology A: Chemistry 281(2014) 47-52. 


\section{Author Biographies}

Jiali Liu received her B.Sc in Applied Chemistry in 2014 from Qilu University of Technology. Presently, she is a graduate student at Qilu University of Technology. Her current research interest is synthesis of fluorescent probe.

Hongdong Duan received his Ph.D. degree in 2002 from Zhejiang University. At present, he is a professor in School of Chemistry and Pharmaceutical Engineering at Qilu University of Technology (PR China). Fluorescent sensors is one of his research fields. 
Table. 1. HOMO and LUMO energy and gap of compounds.

Table 2. Photophysical data of compounds 2 and 4.

Scheme. 1. The synthetic routes of compounds 1-4.

Fig. 1. Optimized molecular Structures and corresponding orbital electron distribution of compounds 2 .

Fig. 2. Optimized molecular Structures and corresponding orbital electron distribution of compounds 4 .

Fig.3. Effect of response time on the fluorescence intensity of compound 2 and 4 (1 $\times$ $\left.10^{-5} \mathrm{M}\right)$ in the presence of $10 \mu \mathrm{M} \mathrm{Zn^{2+ }}$.

Fig.4. Effect of $\mathrm{pH}$ on the fluorescence intensity of compound 2 and $4\left(1 \times 10^{-5} \mathrm{M}\right)$ in

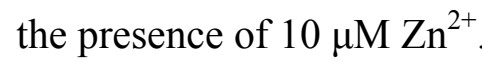

Fig. 5. Changes in the absorbance spectra of compound $2\left(1.0 \times 10^{-5} \mathrm{M}\right)$ in the presence of different metal ions $\left(1.0 \times 10^{-5} \mathrm{M}\right)$ in DMF solution.

Fig. 6. Changes in the absorbance spectra of compound $4\left(1.0 \times 10^{-5} \mathrm{M}\right)$ in the presence of different metal ions $\left(1.0 \times 10^{-5} \mathrm{M}\right)$ in DMF solution.

Fig. 7. Fluorescence spectra response of compound $2\left(1.0 \times 10^{-5} \mathrm{M}\right)$ upon addition of $\mathrm{Zn}^{2+}, \mathrm{Ag}^{+}, \mathrm{Al}^{3+}, \mathrm{Cd}^{2+}, \mathrm{Cu}^{2+}, \mathrm{Fe}^{3+}, \mathrm{Hg}^{2+}, \mathrm{K}^{+}$and $\mathrm{Pb}^{2+}$ ions in DMF solution.

Fig. 8. Fluorescence spectra response of compound $4\left(1.0 \times 10^{-5} \mathrm{M}\right)$ upon addition of $\mathrm{Zn}^{2+}, \mathrm{Ag}^{+}, \mathrm{Al}^{3+}, \mathrm{Cd}^{2+}, \mathrm{Cu}^{2+}, \mathrm{Fe}^{3+}, \mathrm{Hg}^{2+}, \mathrm{K}^{+}$and $\mathrm{Pb}^{2+}$ ions in DMF solution.

Fig. 9. Fluorescence spectra of compound $2\left(1.0 \times 10^{-5} \mathrm{M}\right)$ in DMF solution at different concentrations of $\mathrm{Zn}^{2+}$. $\left(\left[\mathrm{Zn}^{2+}\right]=10^{-5}-10^{-9} \mathrm{M}\right)$. 
Fig. 10. Fluorescence spectra of compound $4\left(1.0 \times 10^{-5} \mathrm{M}\right)$ in DMF solution at different concentrations of $\mathrm{Zn}^{2+}$. $\left(\left[\mathrm{Zn}^{2+}\right]=10^{-5}-10^{-9} \mathrm{M}\right)$.

Fig.11. The normalized fluorescence spectra of $1.0 \mu \mathrm{M}$ compound 2 after addition of increasing amounts of $\mathrm{Zn}^{2+}(0,0.1,0.3,0.5,0.7,0.9,1.0,1.2 \mu \mathrm{M})$ at room temperature. Fig.12. The normalized fluorescence spectra of $1.0 \mu \mathrm{M}$ compound $\mathbf{4}$ after addition of increasing amounts of $\mathrm{Zn}^{2+}(0,0.1,0.3,0.5,0.7,0.9,1.0,1.2 \mu \mathrm{M})$ at room temperature. 


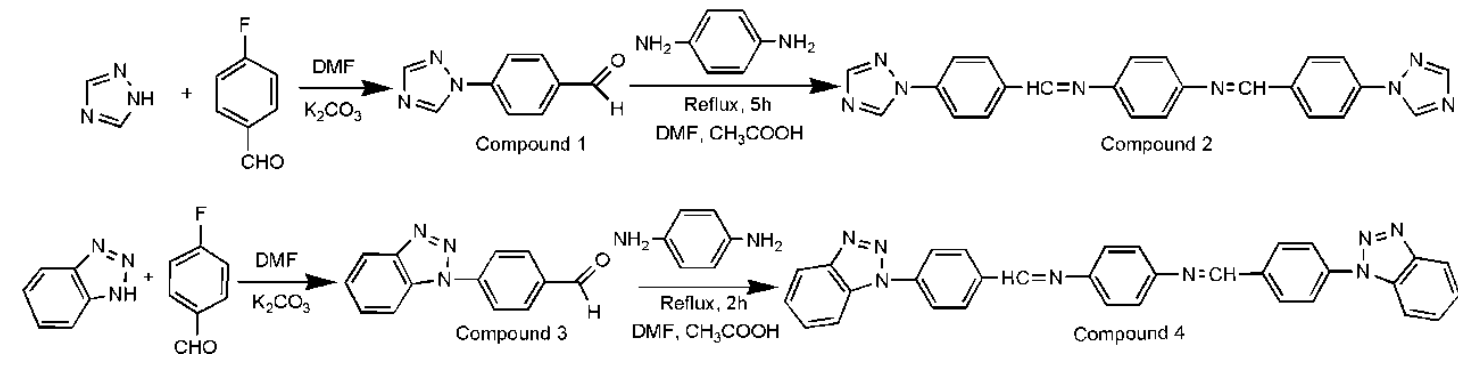

Scheme. 1. The synthetic routes of compounds 1-4. 
Compound 2

Energy/eV

Structure

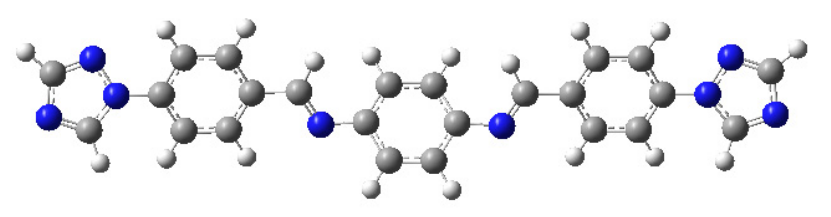

LUMO+1

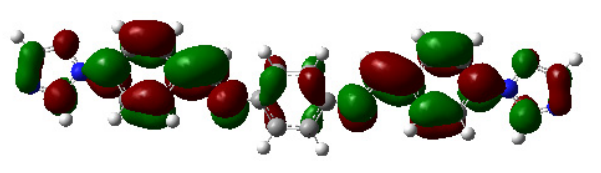

$-0.9$

LUMO

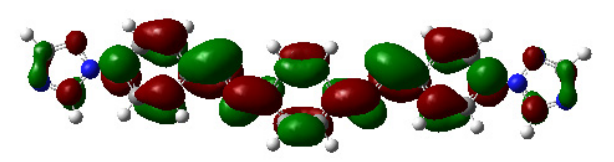

$-1.5$

HOMO

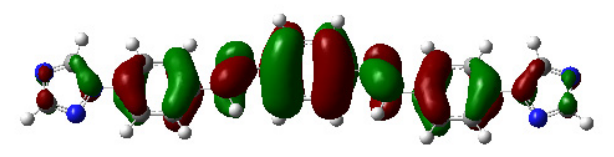

$-6.5$

HOMO-1

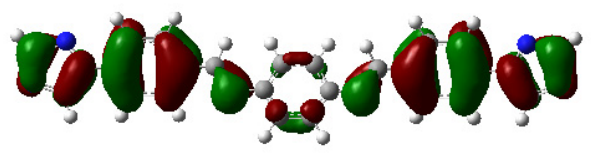

$-7.4$

HOMO-2

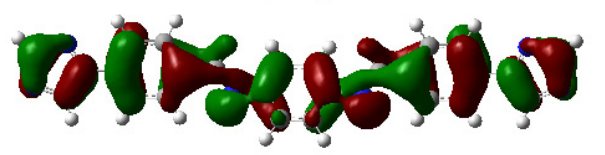

$-7.7$

Fig. 1. Optimized molecular Structures and corresponding orbital electron distribution of compounds 2 . 


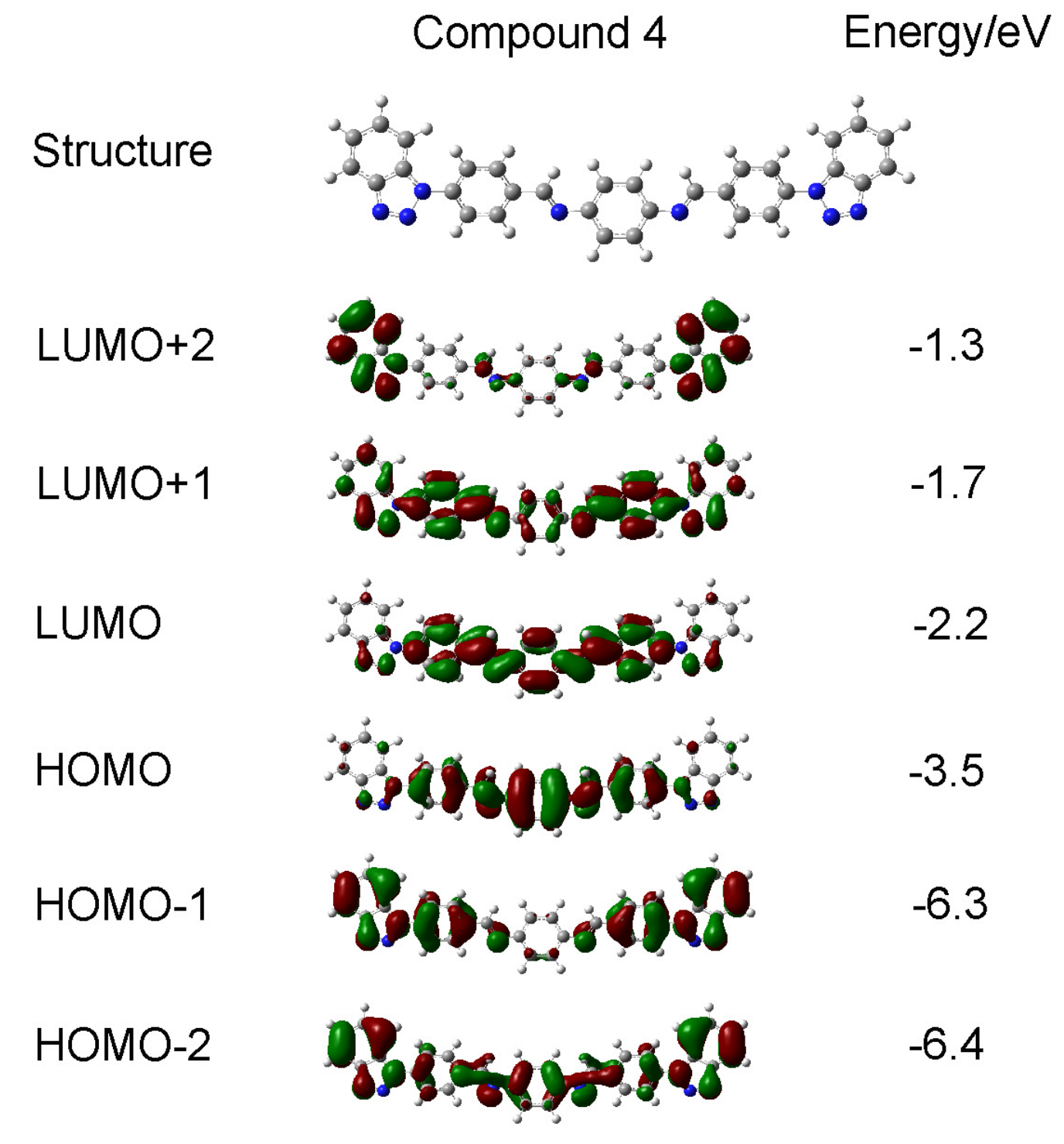

Fig. 2. Optimized molecular Structures and corresponding orbital electron distribution of compounds 4 . 


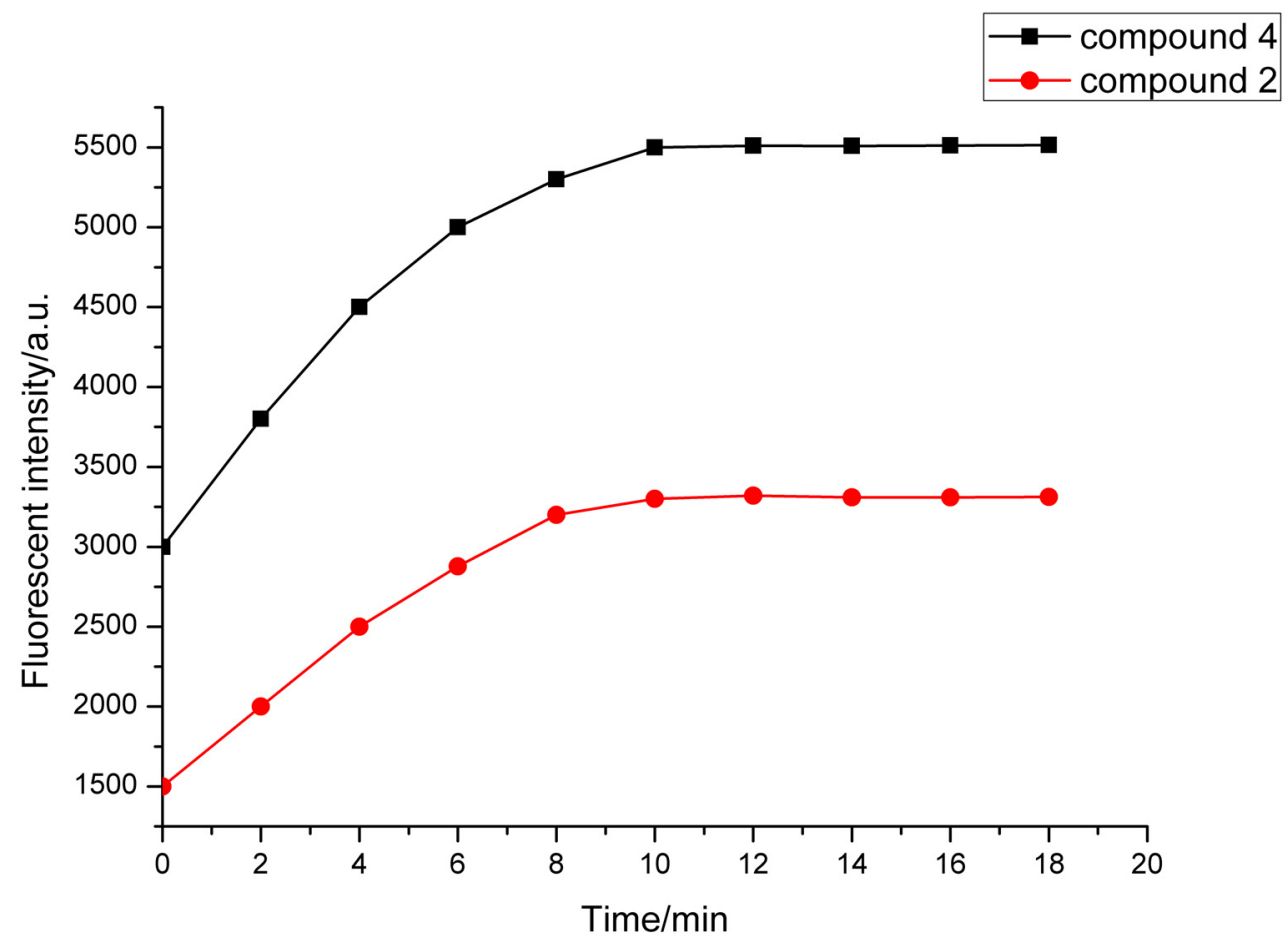

Fig.3. Effect of response time on the fluorescence intensity of compound 2 and 4 ( $1 \times$

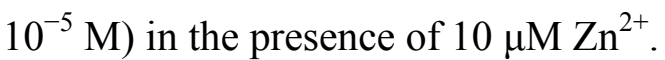




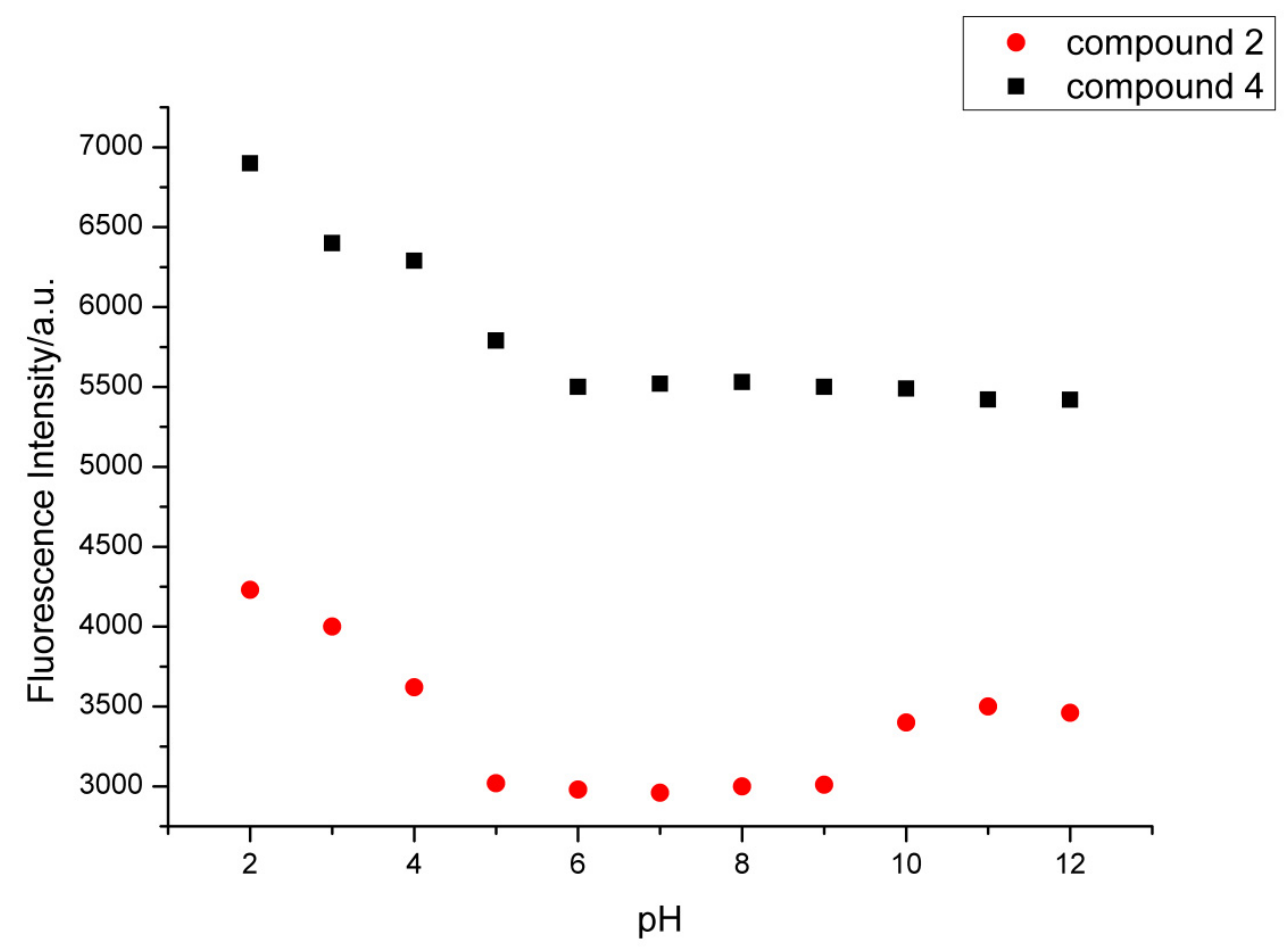

Fig.4. Effect of $\mathrm{pH}$ on the fluorescence intensity of compound 2 and $4\left(1 \times 10^{-5} \mathrm{M}\right)$ in

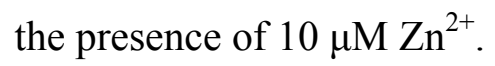




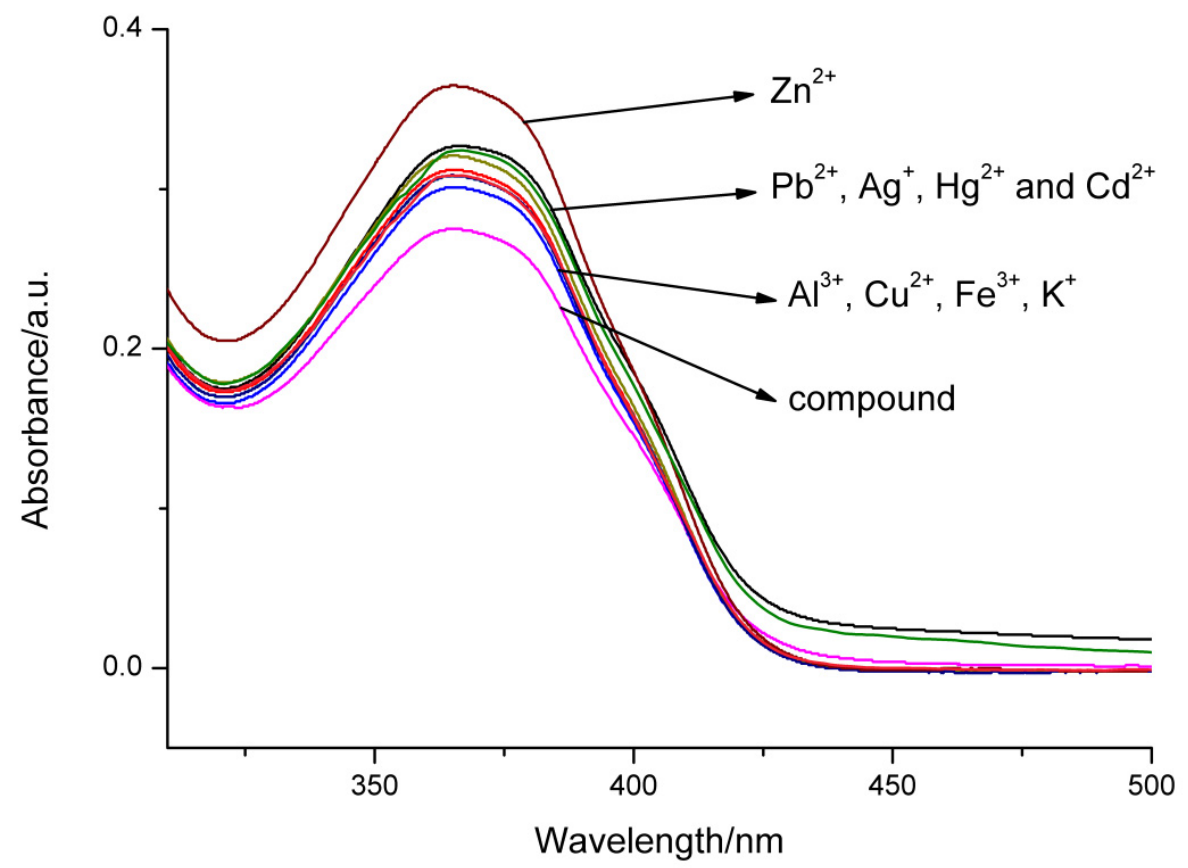

Fig. 5. Changes in the absorbance spectra of compound $2\left(1.0 \times 10^{-5} \mathrm{M}\right)$ in the presence of different metal ions $\left(1.0 \times 10^{-5} \mathrm{M}\right)$ in DMF solution. 


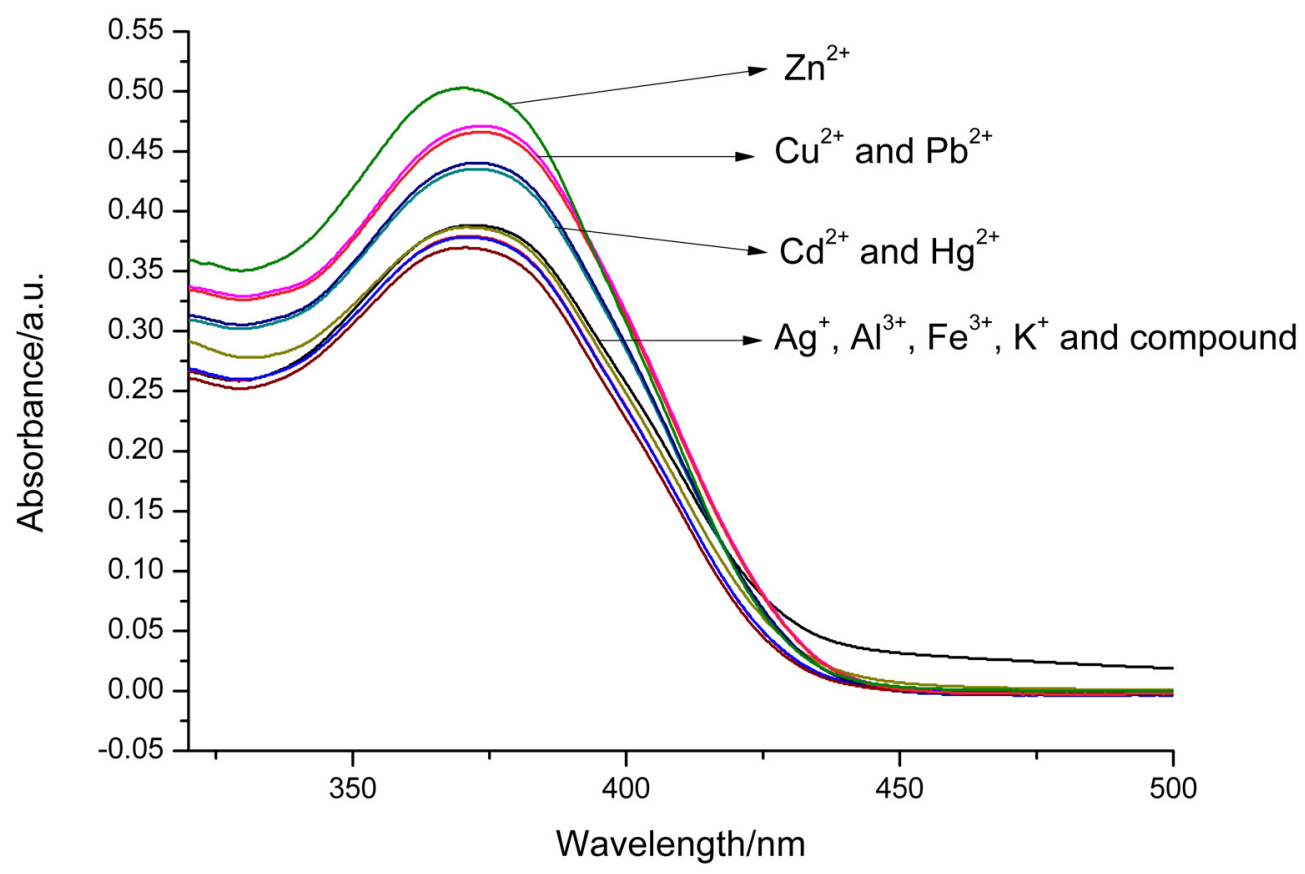

Fig. 6. Changes in the absorbance spectra of compound $4\left(1.0 \times 10^{-5} \mathrm{M}\right)$ in the presence of different metal ions $\left(1.0 \times 10^{-5} \mathrm{M}\right)$ in DMF solution. 


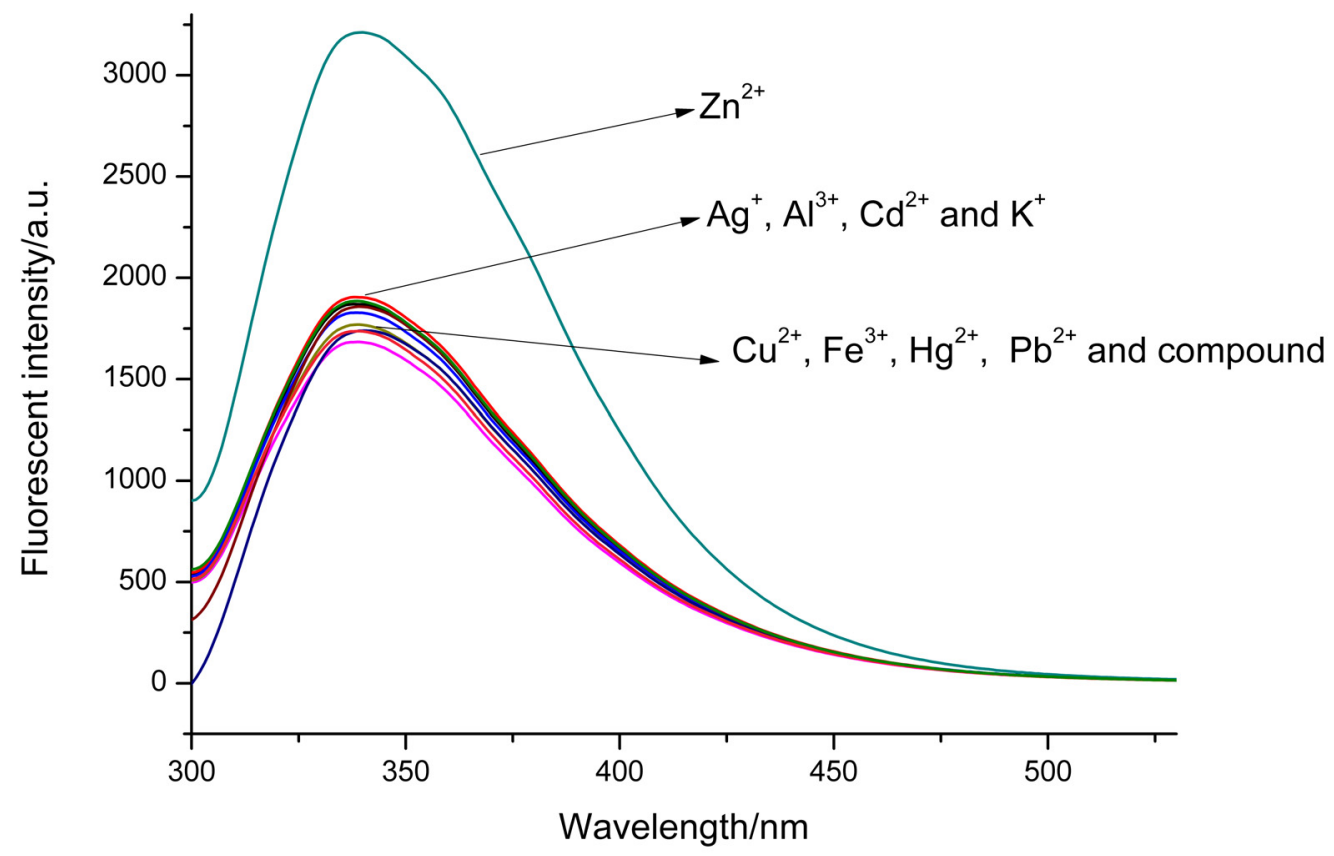

Fig. 7. Fluorescence spectra response of compound $2\left(1.0 \times 10^{-5} \mathrm{M}\right)$ upon addition of $\mathrm{Zn}^{2+}, \mathrm{Ag}^{+}, \mathrm{Al}^{3+}, \mathrm{Cd}^{2+}, \mathrm{Cu}^{2+}, \mathrm{Fe}^{3+}, \mathrm{Hg}^{2+}, \mathrm{K}^{+}$and $\mathrm{Pb}^{2+}$ ions in DMF solution. 


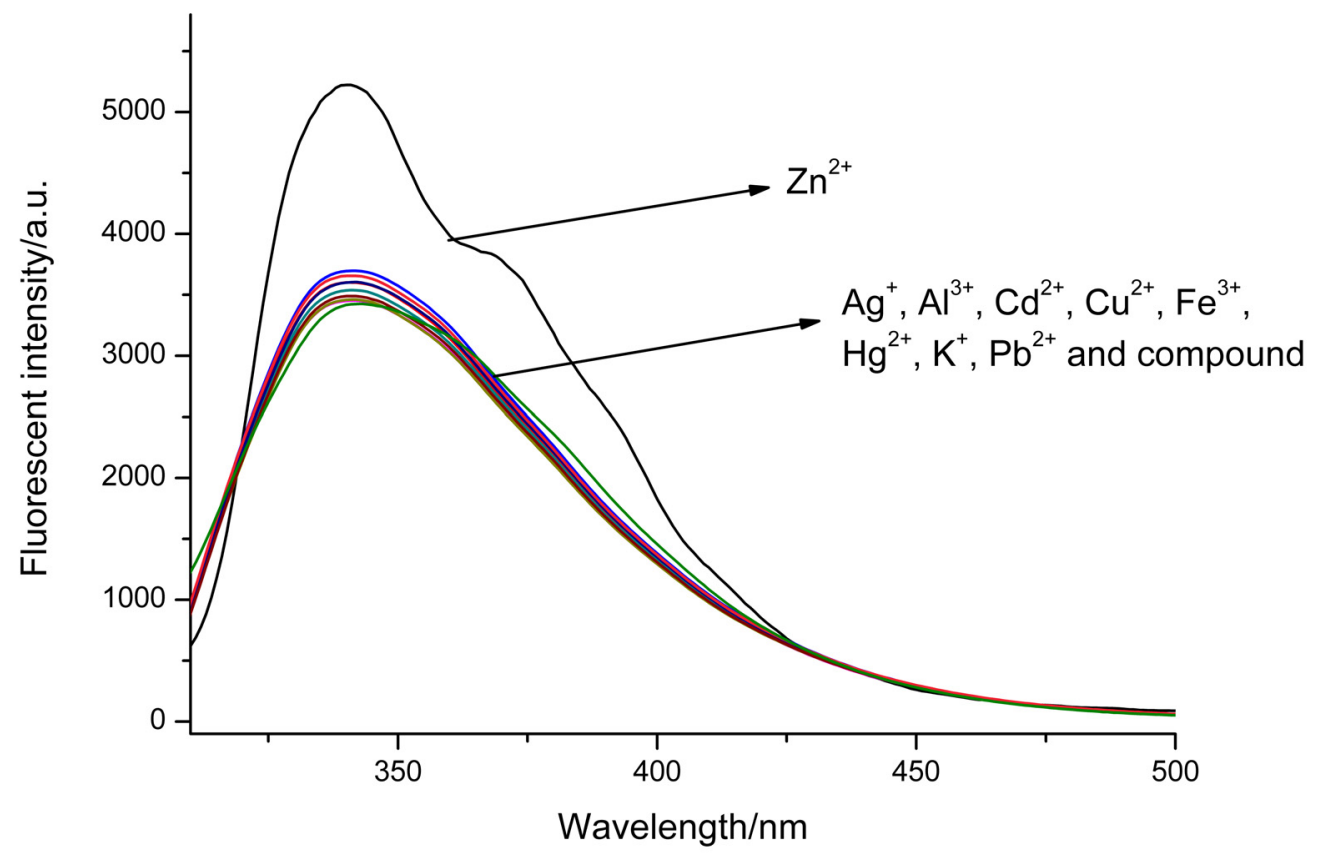

Fig. 8. Fluorescence spectra response of compound $4\left(1.0 \times 10^{-5} \mathrm{M}\right)$ upon addition of $\mathrm{Zn}^{2+}, \mathrm{Ag}^{+}, \mathrm{Al}^{3+}, \mathrm{Cd}^{2+}, \mathrm{Cu}^{2+}, \mathrm{Fe}^{3+}, \mathrm{Hg}^{2+}, \mathrm{K}^{+}$and $\mathrm{Pb}^{2+}$ ions in DMF solution. 


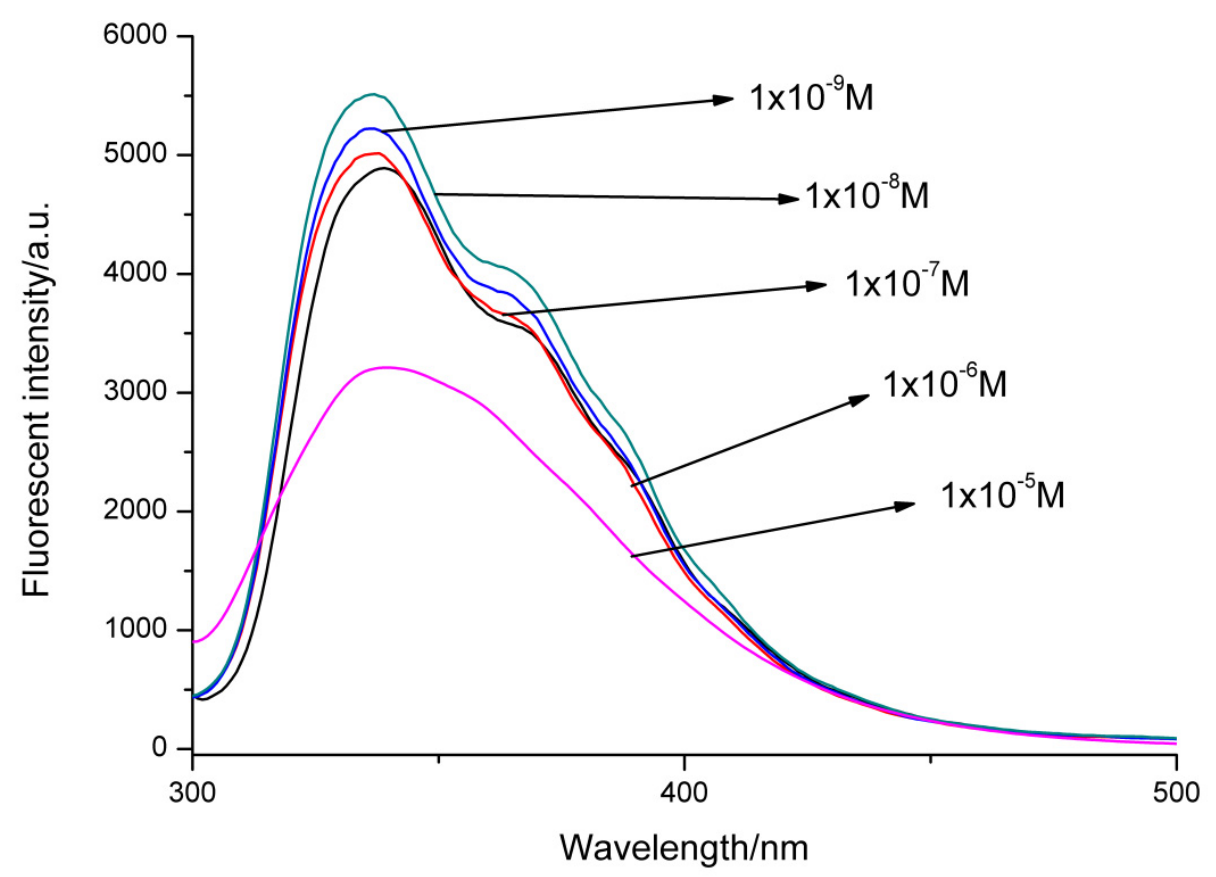

Fig. 9. Fluorescence spectra of compound $2\left(1.0 \times 10^{-5} \mathrm{M}\right)$ in DMF solution at different concentrations of $\mathrm{Zn}^{2+}$. $\left(\left[\mathrm{Zn}^{2+}\right]=10^{-5}-10^{-9} \mathrm{M}\right)$. 


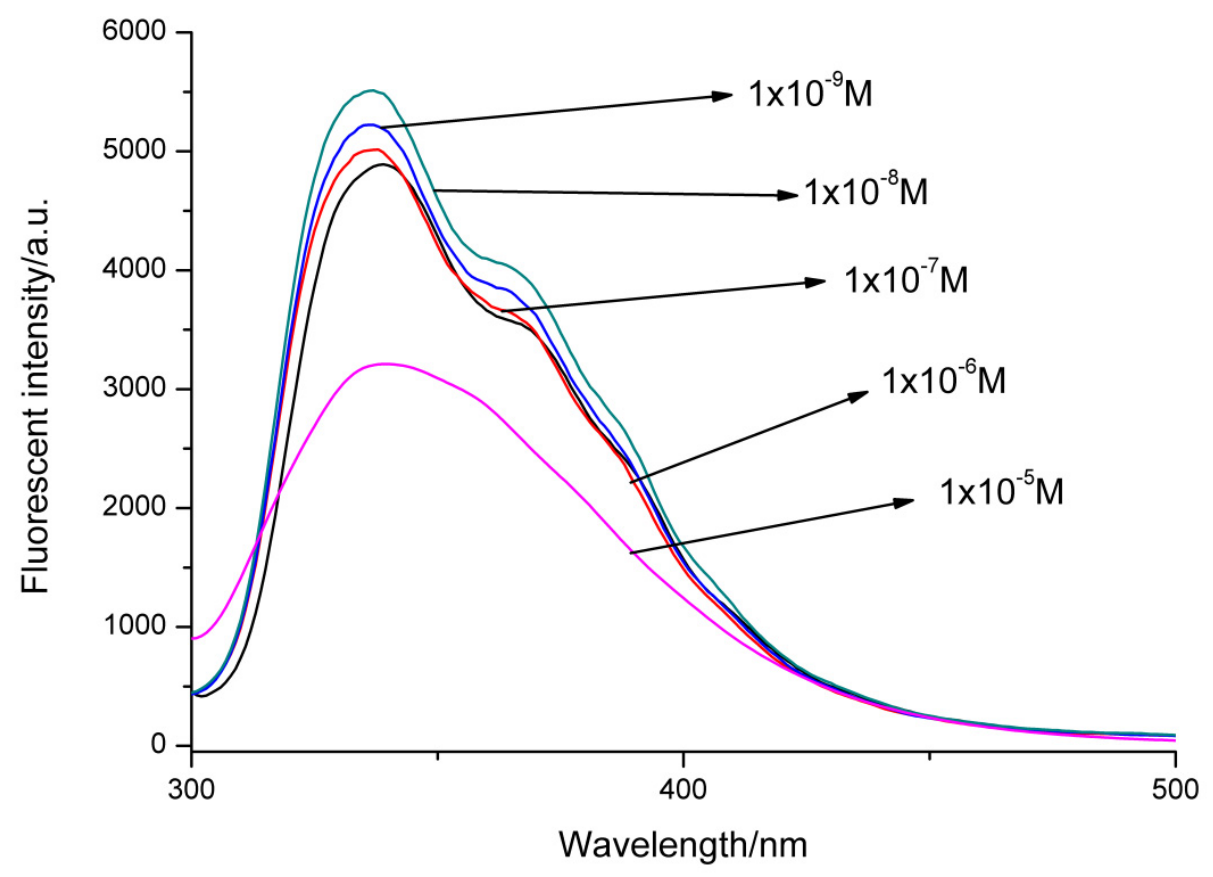

Fig. 10. Fluorescence spectra of compound $4\left(1.0 \times 10^{-5} \mathrm{M}\right)$ in DMF solution at different concentrations of $\mathrm{Zn}^{2+}$. $\left(\left[\mathrm{Zn}^{2+}\right]=10^{-5}-10^{-9} \mathrm{M}\right)$. 


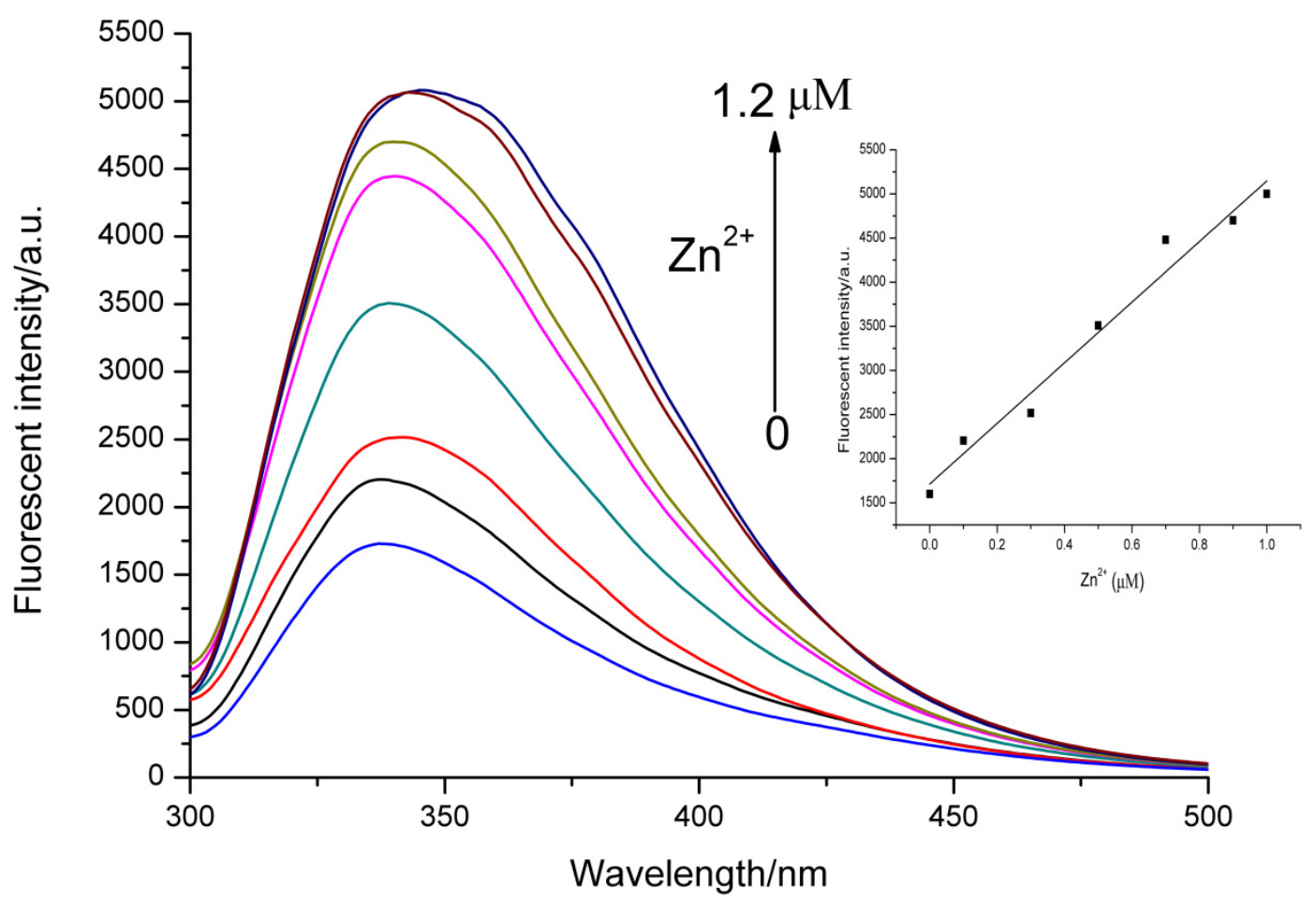

Fig.11. The normalized fluorescence spectra of $1 \mu \mathrm{M}$ compound 2 after addition of increasing amounts of $\mathrm{Zn}^{2+}(0,0.1,0.3,0.5,0.7,0.9,1.0,1.2 \mu \mathrm{M})$ at room temperature. 


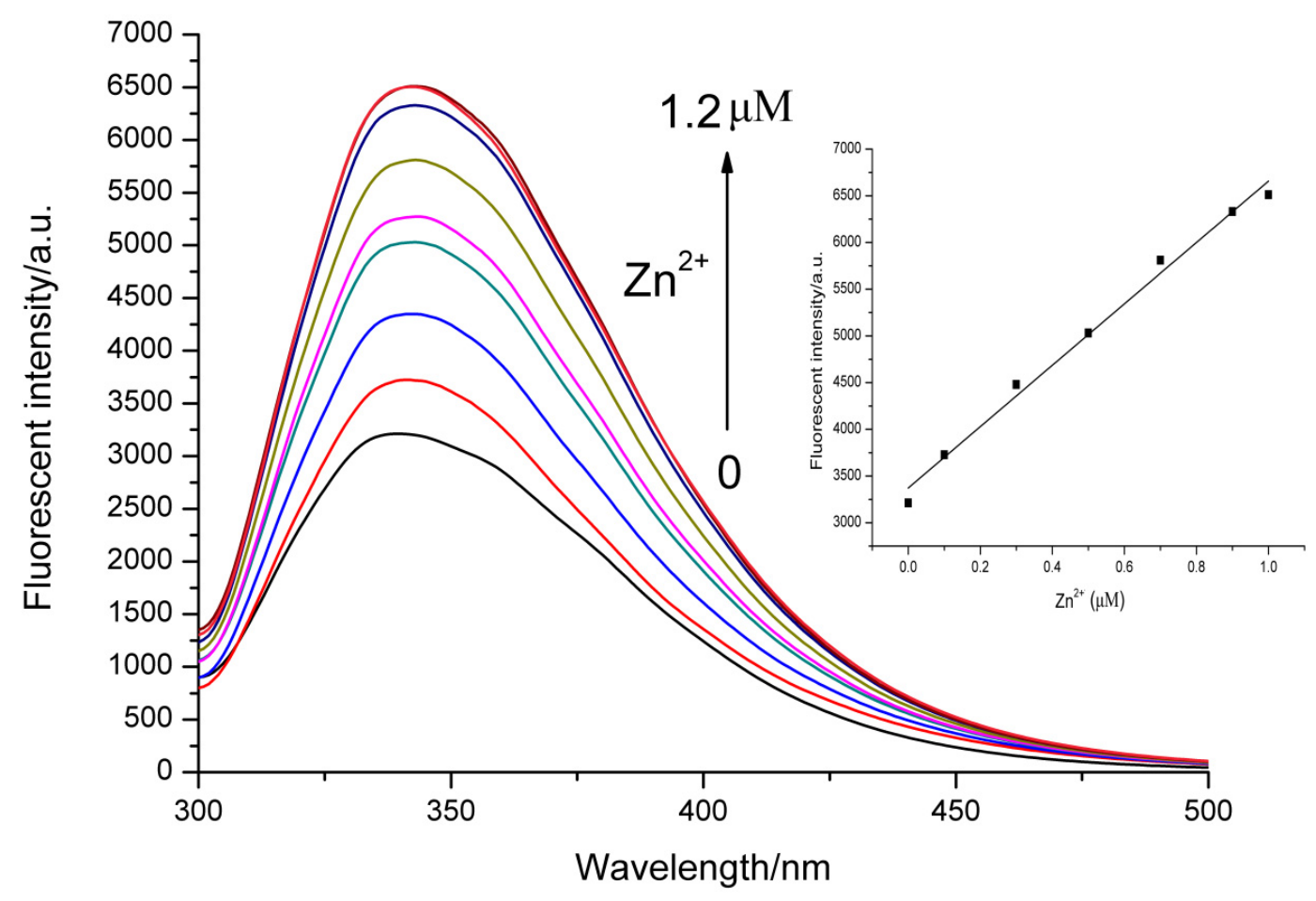

Fig.12. The normalized fluorescence spectra of $1.0 \mu \mathrm{M}$ compound 4 after addition of increasing amounts of $\mathrm{Zn}^{2+}(0,0.1,0.3,0.5,0.7,0.9,1.0,1.2 \mu \mathrm{M})$ at room temperature. 
Table 1

HOMO and LUMO energy and gap of compounds

\begin{tabular}{cccl}
\hline Compound & $\mathrm{E}_{\text {HOMO }}(\mathrm{eV})$ & $\mathrm{E}_{\mathrm{LumO}}(\mathrm{eV})$ & $\Delta \mathrm{E}(\mathrm{eV})$ \\
\hline 2 & -6.5 & -1.5 & 5.0 \\
4 & -3.5 & -2.2 & 1.3 \\
\hline
\end{tabular}


Table 2

Photophysical data of compounds 2 and 4

\begin{tabular}{clcl}
\hline Compound & $\lambda_{\text {abs }}(\mathrm{nm})$ & $\lambda_{\mathrm{em}}(\mathrm{nm})$ & $\mathrm{I}\left(\mathrm{cm}^{-1}\right)$ \\
\hline 2 & 365 & 338 & -4569.25 \\
4 & 372 & 342 & -4240.80 \\
\hline
\end{tabular}

I: Stocks shift $=1 /\left(1 / \lambda_{\text {abs }}-1 / \lambda_{\text {em }}\right)$ 